\title{
Effect Of Drag Models In Two-Phase Solid-Gas Particles Ceria- Nitrogen: A Hydrodynamic Study Of The Fluidized Bed Reactor
}

\author{
${ }^{1}$ Priyanka Swarnkar, ${ }^{2}$ T. Sundararajan \\ ${ }^{1,2}$ Department of Mechanical Engineering, Indian Institute of Technology Madras, Chennai 600036, India \\ ${ }^{1}$ me15d059@smail.iitm.ac.in, ${ }^{2}$ tsundar@iitm.ac.in
}

\begin{abstract}
A two-dimensional solid-gas ceria-nitrogen fluidized bed reactor (FBR) used for the thermochemical water splitting process was considered to study the bed hydrodynamics of ceria particles with sphericity 1 . Ansys Fluent v19.0 was used for simulation. The numerical model for FBR is validated against the experiment and simulation results conducted with the spherical glass beads of particles size $275 \mu \mathrm{m}$ from the available literature based on the multi-fluid Eulerian-Eulerian model integrated with the solid particle kinetic theory approach. The simulation results of pressure drop, and simulation and experimental results from the literature for instantaneous voidage and time mean voidage predictions compares well with the literature. The solid-gas ceria-nitrogen with the particle diameter $300 \mu \mathrm{m}$ was considered for the hydrodynamic study. The effect of different drag models on the expanded bed height was studied. Different drag models Huilin-Gidaspow, Wen-Yu, Syamlal O'Brien, Syamlal O'Brien Para and Gidaspow with the restitution co-efficient of 0.90 were initially used to identify the most appropriate drag model. The simulation results based on different drag models at a fluidization velocity of $0.72 \mathrm{~m} / \mathrm{s}$ shows that the Syamlal O-Brien will be the most appropriate drag model to study the bed hydrodynamics as it minimizes the overprediction. Then rest of the study was carried out for a range of fluidization velocity $0.24,0.48,0.72,0.96,1.2$, and $1.44 \mathrm{~m} / \mathrm{s}$ with the Syamlal-O’Brien drag model.
\end{abstract}

Keywords: fluidized bed reactor, simulation, two-dimensional, gas-solid flow, CFD, hydrodynamics

\section{Introduction}

Different types of reactors used commercially, such as packed bed reactors, porous bed reactors, foam bed reactors, and FBR. Packed bed and FBR are the most commonly used chemical reactors for non-catalytic solid-gas reactions ${ }^{[1]}$. FBR are superior to packed bed reactors as it offers uniform gas-solid mixing, particle fluidization, and heat transfer from the gas phase to the particulate phase. Because of this reason, it has gained significant attention in the past 20 years and is preferred particularly for exothermic or endothermic reaction ${ }^{[2]}$. The solid particles fluidizing in the FBR plays a crucial role as it undergoes physical processes like heat transfer, absorption, and transportation. This technology is used in pharmaceutical, mineral, chemical, and energy-related process industries. The FBR encompasses particles in motion, and for this reason, an interface exists between them, which is not known and is dynamic. ${ }^{[3]}$ described all those solid-gas interfaces by continuum mechanics and solved the governing equation at the boundary condition. At the same time, the non-linear equations involved in the mathematical modelling for solving the interpenetrating and dynamic phase adds more complexities to the numerical solutions. ${ }^{[4]}$ stated that the assumption of specific parameters like interaction and transient at the interface for the modelling of FBR hydrodynamics does encounter the same issue. As the interface between the two phases is not known and is dynamic. Therefore, it is essential to understand the fluidized bed hydrodynamics.

Computational Fluid Dynamics CFD in the computational field is a promising tool for modelling multiphase flow hydrodynamics. Two approaches generally considered in two-phase solid-gas fluidized bed modelling are the EulerianLagrangian approach which works on the Discrete Element Method (DEM) and Eulerian-Eulerian approach this method treats both the phases as interpenetrating continua. The conversation equation for energy, mass, and momentum are solved for both the phases separately. The eulerian-eulerian method uses the kinetic theory of granular flow (KTGF) for solving the solid phase ${ }^{[5]}$.

Eulerian-Lagrangian two-phase flow solves the governing equations for every single particle by incorporating the particle collision and the force applied on the particle by the gas. Hard sphere ${ }^{[6]}$ or soft sphere ${ }^{[7]}$ approach is used to model particle-particle collisions. DEM calculates the particle velocity and its trajectory for interactions occurred due to multiphase collision ${ }^{[8]}$. This model is more useful for dilute systems where the continuum model is not suitable. DEM, despite its advantage in solving every individual phase it is computationally costly and therefore is applicable for a small number of 
particles. Here arrives the need of using Eulerian-Eulerian approach. In this approach, both the phases are treated as interpenetrating continuum ${ }^{[9]}$. The governing equations such as mass momentum and continuity are solved with appropriate boundary conditions and jump conditions for the interface. In this approach, the solid particles posses specific identical density and diameter. The solid-state continuum approximation do not possess equation of state, normal stress, and viscosity ${ }^{[9]}$ and therefore, some averaging schemes and assumptions are necessary for momentum balance of solid phase. Those averaging schemes can then be applied to develop a continuum for per phase to extend the Eulerian description from single to multiphase flow. While the transport coefficients of the gas phase that reasonably be interpreted by those with some revisions for a single-phase flow, the transport coefficients of the solid phases should compensate for gas-particle interactions and particle-particle collisions. It is referred to as a drag force. ${ }^{[10,11]}$ considered a range of Reynolds numbers for a spherical particle in a fluid to study the drag force and developed a correlation. When a particle travels in a dispersed two-phase mixture, it experiences drag from the surrounding particles. Various correlations have been reported in the literature for calculating the momentum exchange coefficient of gas-solid models [12-14].

Particle-particle collision with no stress term in the equation adds an additional term to the momentum exchange equation. It is also an essential parameter to identify the hydrodynamics of the FBR. Various correlations ${ }^{[14-16]}$ have been developed to account for the stress term of the solid. The particle collision in FBR is measured by restitution coefficient (RC) where 1 indicates elastic collision and 0 refers to an inelastic collision. Lower the RC is lesser will be the collision resulting in more fluctuating KE ${ }^{[17]} .{ }^{[18]}$ observed that the bubble distribution and its dynamics are responsible for the FBR quality. A large amount of small bubbles with a minimum fluidization velocity of bubbles adds homogeneity to the bed with high-quality fluidization. A two-dimensional multiphase flow bubbling fluidized bed was simulated based on the Eulerian-Eulerian approach with multiple drag models. It was proposed to adjust Di Felice correlation depending on experimental minimum fluidizing velocity. The enhanced version of Di Felice was in good agreement with the experimental data ${ }^{[19]}$.

Much work is available on understanding the hydrodynamics of lower density particle fluidization, but there is limited work available for fluidizing the particle used for thermochemical water splitting process. Therefore, a closer insight into the capabilities of FBR redox reactions urges to study FBR for catalyst fluidization for thermochemical water splitting process. Choosing ceria as a catalyst for redox reaction is because of its unique character of becoming oxygen deficient at a temperature of around $800^{\circ} \mathrm{C}$ and above. The amount of oxygen released depends on how much of its surface is getting exposed to high temperatures. It indicates that a proper mixing of solid-gas is required to enhance the oxygen evolution capacity of the catalyst. Nitrogen is an inert gas, and therefore, it is selected as a fluidizing gas to ensure that FBR should be oxygen deficient. Due to the limitations offered by the experiments in understanding the flow hydrodynamics and to get an insight into the hydrodynamic behaviour of ceria-nitrogen fluidization, keeping in mind the computational cost, a 2D CFD simulation is preferred. There are several parameters like lift models, specularity and restitution coefficient, spatial discretization scheme used and very important: drag models which are the major contributor to the fluidization. Looking into the importance of drag in fluidization, the simulation study was conducted based on different drag models and fluidization velocity.

\section{Problem statement}

The two-dimensional computational domain was replicated from the experimental setup of ${ }^{[20]}$ two-phase solidgas ceria-nitrogen with the particle diameter of $300 \mu \mathrm{m}$. The details of the solid-gas particles are mentioned in Table 1 . Table 2 outlines the models and parameters used in simulating FBR

\subsection{Computational Domain}

To understand and apprehend the hydrodynamics of FBR, the computational domain was created concerning the dimensions of FBR from the experimental work of ${ }^{[20]}$. The Plexiglas column has a height of $1 \mathrm{~m}$ and a width of $0.28 \mathrm{~m}$ based on the experimental setup. Initially, spherical glass beads of a diameter of $275 \mu \mathrm{m}$ and a density of $2500 \mathrm{~kg} / \mathrm{m} 3$ are fluidized by air with atmospheric conditions. The solid volume fraction is 0.6 , and the static bed height is $0.4 \mathrm{~m}$. The total pressure drop and bed expansion was tracked at a $U=0.38 \mathrm{~m} / \mathrm{s}$ and $0.46 \mathrm{~m} / \mathrm{s}$ superficial gas velocity in the test. Fig. 1 (a) represents the geometry \& boundary condition. Fig. 1 (b \& c) depicts the domain and mesh created using the meshing tool ICEM CFD 19.0 Version with a mesh size of $\left(56^{* 200)} \Delta \mathrm{X} \& \Delta \mathrm{Y} 0.005 \mathrm{~m}\right.$. 


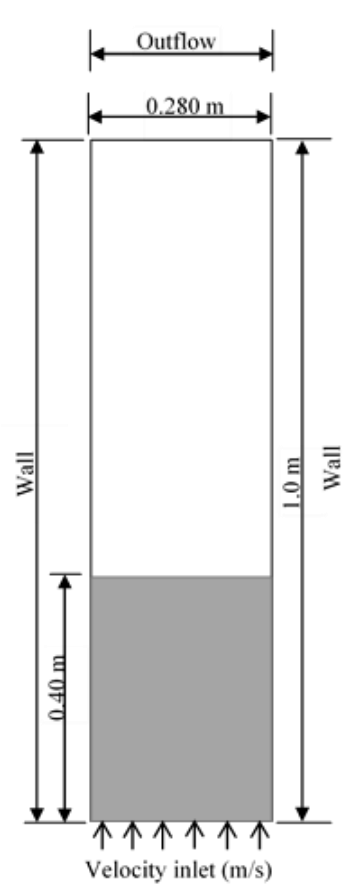

(a)

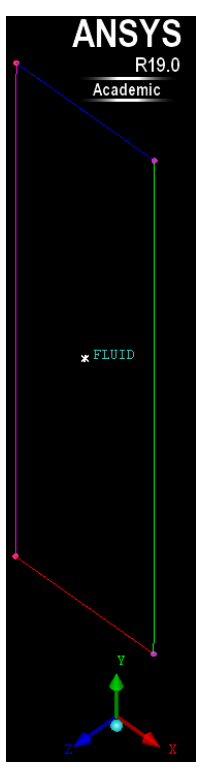

(b)

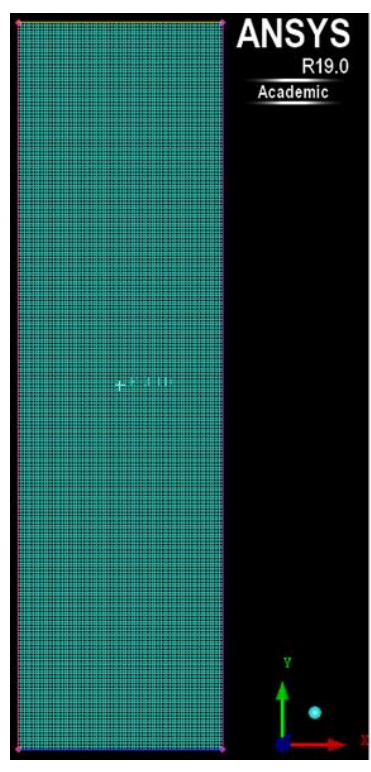

(c)

Fig. 1 (a), (b \& c) represents the computational domain considered for the present study.

Table 1. Properties of the solid particle considered for further studies

\begin{tabular}{llcl}
\hline Parameters & Unit & Value & Remark \\
\hline Diameter of particles $d_{p}$ & $\mu \mathrm{m}$ & $275 \& 300$ & glass bead \& cerium di-oxide \\
Density of particles $\rho_{p}$ & $\mathrm{~kg} / \mathrm{m}^{3}$ & 2500 & Glass-beads \\
& & 7220 & Cerium di-oxide \\
Gas density $\rho_{g}$ & $\mathrm{~kg} / \mathrm{m}^{3}$ & 1.225 & $\mathrm{Air}$ \\
& & 1.138 & $\mathrm{~N}_{2}$ \\
Specific heat capacity of $C_{g}$ & $\mathrm{~J} / \mathrm{kg} \cdot \mathrm{K}$ & 1005 & $\mathrm{Air}$ \\
& & 1016.56 & $\mathrm{~N}_{2}$ \\
Viscosity $\mu$ & $\mathrm{Pa} \cdot \mathrm{s}$ & $2.25 \mathrm{e}^{-05}$ & $\mathrm{~N}_{2}$ \\
Minimum fluidization velocity $U_{m f}$ & $\mathrm{~m} / \mathrm{s}$ & $1.81 \mathrm{e}^{-05}$ & Air \\
& & $0.07 \&$ glass bead \& ceria \\
\hline
\end{tabular}

Table 2. Models considered for Ansys Fluent v 19.0 Simulations of FBR

\begin{tabular}{ll}
\hline Settings & Values \\
\hline Solver & Pressure \\
Formulation & Implicit \\
Velocity Formulation & Absolute \\
Time & Transient, first-order upwind \\
Unsteady formulation & $1^{\text {st }}$ order implicit \\
Multiphase model & Eulerian-Granular \\
Viscous model & Laminar \\
Granular viscosity, Solid pressure \& Radial & Syamlal-O'brien ${ }^{[13]}$ \\
distribution & Lun et al. ${ }^{[21]}$ \\
Granular bulk viscosity & Schaffer \\
Frictional viscosity & Based-ktgf ${ }^{[22]}$ \\
Frictional pressure &
\end{tabular}




\begin{tabular}{|c|c|}
\hline Granular temperature & Algebraic \\
\hline Packing limit & 0.63 \\
\hline Pressure velocity coupling & Coupled PC-SIMPLE ${ }^{[23]}$ \\
\hline Momentum. & $1^{\text {st }}$ Order Upwind \\
\hline Spatial discretization: Volume fraction & $1^{\text {st }}$ Order Upwind \\
\hline Gradient & Least square cell-based \\
\hline Bed height & $0.4 \mathrm{~m}$ \\
\hline Drag law & $\begin{array}{l}\text { Syamlal-O'Brien, Syamlal O'Brien Para, } \\
\text { Huilin Gidaspow, Gidaspow, \& Wen-Yu } \\
{[13,14,24]}\end{array}$ \\
\hline Restitution coefficient & 0.90 \\
\hline Inlet boundary & $\begin{array}{l}\text { Velocity inlet }(0.38,0.46 \mathrm{~m} / \mathrm{s}) \text { for glass beads } \\
\&(0.24,0.48,0.72,1.2,1.44 \mathrm{~m} / \mathrm{s}) \text { for ceria } \\
\text { particles }\end{array}$ \\
\hline Outlet boundary & outflow \\
\hline Wall boundary & No-slip \\
\hline Time step size \& number of time step & $0.001 \& 25000(25 \mathrm{sec})$ \\
\hline Iterations per time step & 50 \\
\hline
\end{tabular}

\section{Results and Discussion}

\subsection{Validation}

Fig 2 (a) Compares the simulated bed pressure drop and instantaneous voidage fraction with the simulated result and Fig. 2 (b) compared the simulated time-averaged local voidage profiles against the experimental results of [20]. The comparison was made for glass bead-air fluidization with a particle diameter of $275 \mu \mathrm{m}$ at a fluidization velocity of $U_{\mathrm{mf}}=$ 0.38 and $0.46 \mathrm{~m} / \mathrm{s}$ at a height $\mathrm{z}=0.2 \mathrm{~m}$. These plots reflect that the present simulations are in good agreement with simulation and experimental results of. From here onwards the same simulation parameters were used to study the bed hydrodynamics based on range of $U_{\mathrm{mf}}=0.42-1.44 \mathrm{~m} / \mathrm{s}$ with a drag model Syamlal O'Brien. Subsequently, the effect of different drag models on solid-gas fluidization at $\mathrm{U}_{\mathrm{mf}}=0.72 \mathrm{~m} / \mathrm{s}$ was studied.
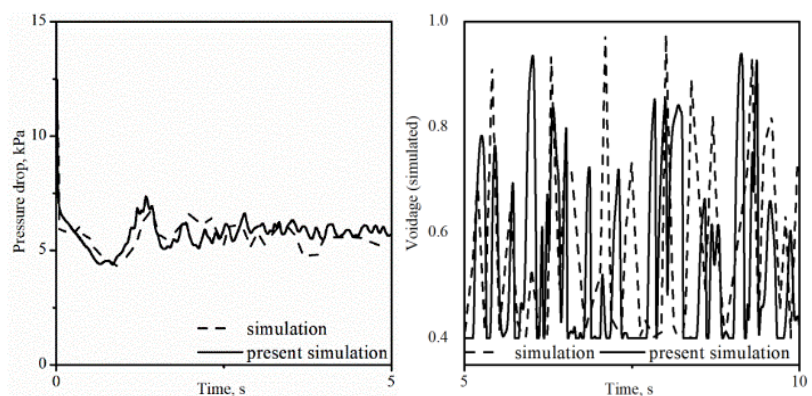

(a)

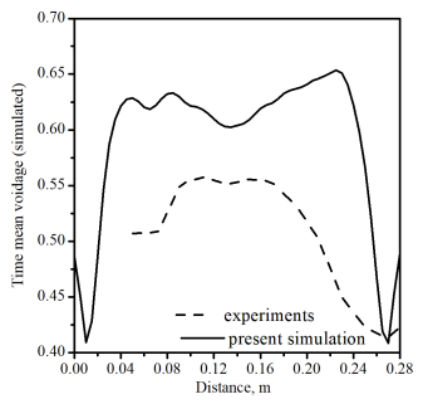

(b)

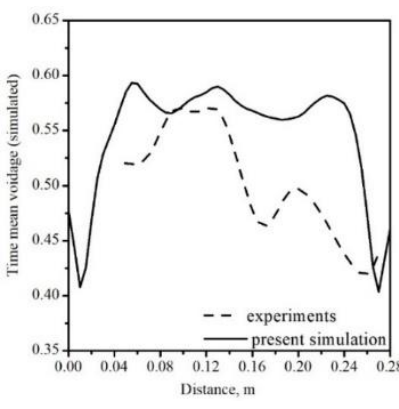

Fig. 2 Compares the simulated bed pressure drop and voidage w.r.t time $\&$ time averaged local voidage fraction with experimental data w.r.t distance at $\mathrm{U}=0.38 \mathrm{~m} / \mathrm{s}$ (left) \& $\mathrm{U}=0.46 \mathrm{~m} / \mathrm{s}$ (right), $\mathrm{z}=0.2 \mathrm{~m}^{[20]}$.

\subsection{Grid Independent Test}

A 2D computational domain for solid-gas ceria-nitrogen fluidization was discretized using a uniform grid spacing of 3 , 4 and $5 \mathrm{~mm}$ for grid-independent test. Fig. 3 Compares the pressure drop profile vs time for 3,4 and $5 \mathrm{~mm}$ grid size, the pressure drop profile is almost similar in all the three cases. The fluctuation in the pressure drop from time $0-5 \mathrm{~s}$ reflects the split and coalesce of bubbles in transient fashion inside FBR. Based on the particle size of $300 \mu \mathrm{m}$ and Euler-Euler model where it requires a cell size $\Delta \mathrm{x} \& \Delta \mathrm{y} \geq 10$ times of particle diameter, a $5 \mathrm{~mm}$ grid size was selected for CFD simulation. The total real-time simulation was performed for 25 seconds, for the first 0-5 seconds, a transient simulation was carried out without time averaging, and after the steady-state was reached, the simulation was performed for 20 seconds with time averaging. 


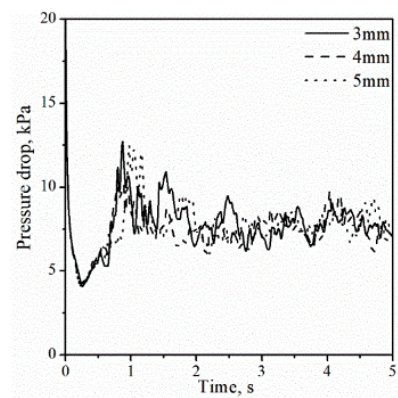

Fig. 3 Simulated bed pressure drop at $\mathrm{z}=0.2 \mathrm{~m}$, drag model: Syamlal-O'Brien at $\mathrm{U}=0.72 \mathrm{~m} / \mathrm{s}, \mathrm{e}_{\mathrm{ss}}=0.90$.

Two parameters, drag models and fluidization velocity was considered for numerical simulation with the view of understanding the fluidization of ceria-nitrogen. The total run time for simulation was $25 \mathrm{~s}$, where transient simulation was performed from 0-5 s, then after achieving steady-state, time-averaged simulation was run for 5-25 s. Fig. 4 represents the contour plots of instantaneous local solid volume fraction based on different drag models Syamlal-O'Brien, Syamlal-O'Brien Para \& Gidaspow Huilin-Gidaspow \& Wen-Yu at a fluidization velocity and restitution co-efficient of $U=0.72 \mathrm{~m} / \mathrm{s} \mathrm{e}_{\mathrm{ss}}=$ 0.90. It was observed that the bed expands symmetrically and gradually from time $0.25-1.5 \mathrm{~s}$, very minimal changes in bed height occurred after 1.5-5 sec, bed expansion became consistency after $1.5 \mathrm{~s}$, indicating that, the bed height has reached steady state. Asymmetry in the bed expansion was also evident until $1.5 \mathrm{sec}$ then after it changed to chaotic transient bubble formation. Upon comparing all the five drag models used, the difference in the bed expansion was observed only till $1.5 \mathrm{~s}$, in which case it was seen that at $1.5 \mathrm{~s}$ syamlal O'Brien and Syamlal O'Brien Para attains closer axisymmetry than compared to Gidaspow, Huilin-Gidaspow, and Wen-Yu.

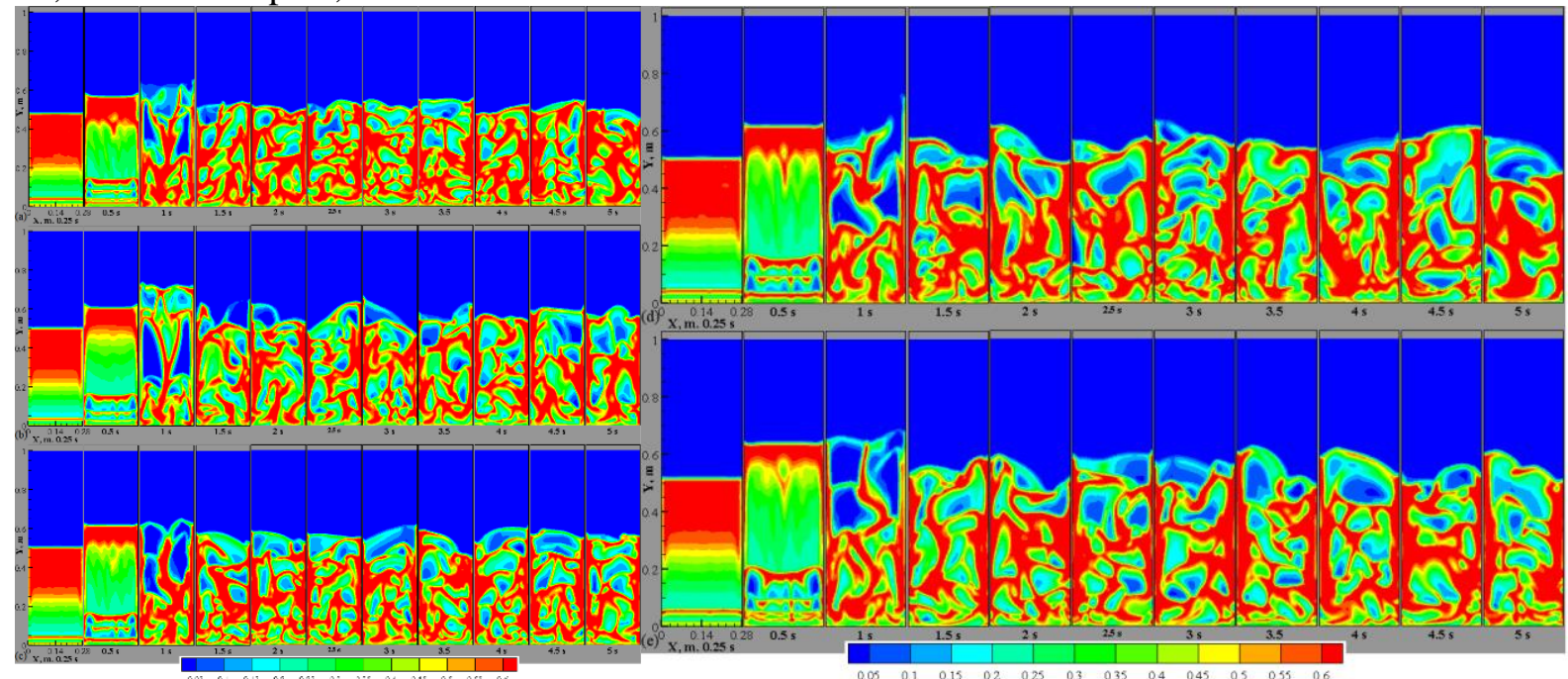

Fig. 4 Simulated instantaneous local solid volume fraction: (a, b \&c) left, drag models: Syamlal-O’Brien, Syamlal-O’Brien Para \& Gidaspow, (d \& e) right, drag models: Huilin-Gidaspow \& Wen-Yu. $\mathrm{U}=0.72 \mathrm{~m} / \mathrm{s} \mathrm{e}_{\mathrm{ss}}=0.90,0-5 \mathrm{~s}$.

Afterwards, all drag models predicted almost a similar trend with minimal changes in solid-gas mixing. Following the flow analysis, the time-averaged simulation was performed from $5 \mathrm{~s}$ for another $20 \mathrm{~s}$. Fig. 5 (a \& b) provides information on bed expansion from 5-25 s on different drag models. It is evident that the max bed height is predicted by the Wen-Yu model, this more massive discrepancy is because, this model is applicable for small solid volume fraction. The remaining four models, Fig. 5 (b) captures almost the same bed expansion heights. 


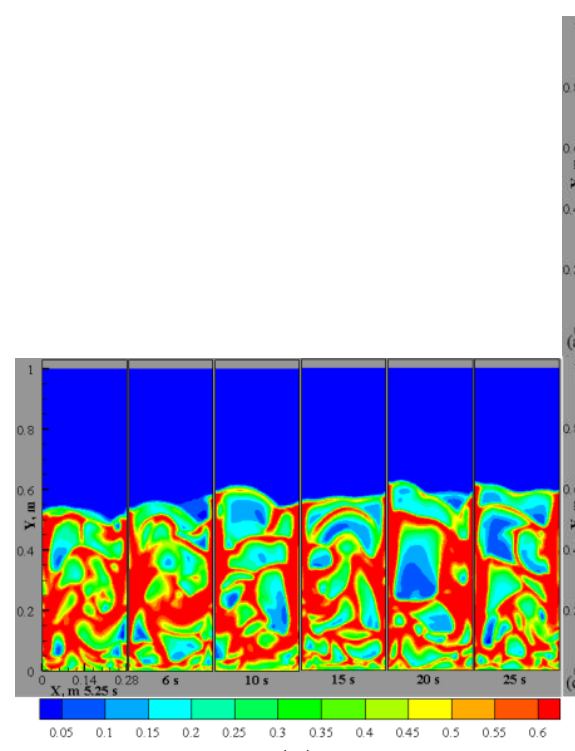

(a)

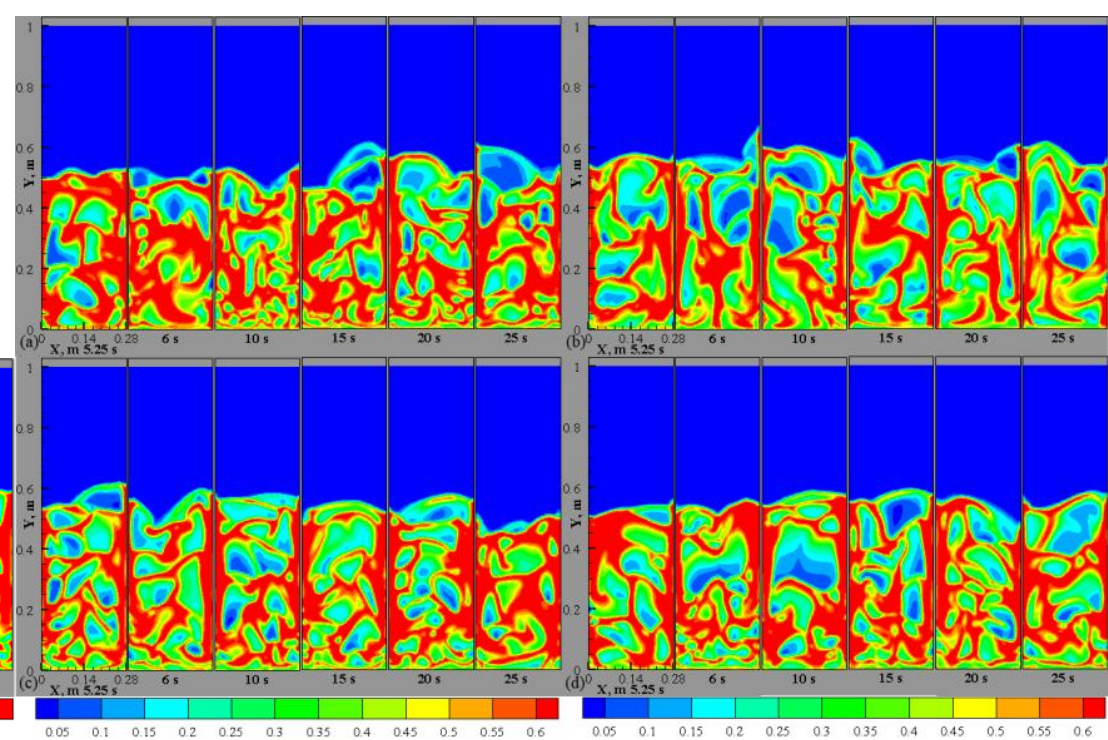

(b)

Fig. 5 (a) Simulated instantaneous local solid volume fraction: drag model: (a) Wen-Yu, (b) (a, b, c \& d) Syamlal-O'Brien, SyamlalO’Brien Para, Gidaspow and Huilin-Gidaspow $\mathrm{U}=0.72 \mathrm{~m} / \mathrm{s}, \mathrm{e}_{\mathrm{ss}}=0.90,5.25-25 \mathrm{~s}$.

To elucidate the fluidized bed behaviour Fig. 6 5-25 s shows the snapshots of the instantaneous local solid volume fraction at different time instances for fluidization velocity $\mathrm{U}_{\mathrm{mf}}=0.24,0.48,0.72,0.96,1.2$ and $1.44 \mathrm{~m} / \mathrm{s}$. The dynamic steady is reached after time $2 \mathrm{~s}$, but to avoid the instability, the time-averaged simulation was carried out after time $5 \mathrm{~s}$. Initially at a minimum fluidization velocity of $0.24 \mathrm{~m} / \mathrm{s}$, no particle fluidization is observed which is evident as this is minimum fluidization velocity, to fluidize the heavy density particle the fluidization velocity between the range of minimum fluidization velocity and the terminal velocity was chosen. It is observed that solid-gas mixing is reasonable at a fluidizing velocity range of $0.72-1.2 \mathrm{~m} / \mathrm{s}$.

Whereas for a fluidization velocity of $0.48 \mathrm{~m} / \mathrm{s}$ the bed starts to expand at time $0.25 \mathrm{~s}$ and very minimal particle are in gas contact with the time progresses, the bubbles start to expand the particles from the bed surface. Gradual increase in bubble size is reflected at time $1 \mathrm{~s}$ then from here onwards the flow achieves dynamic steady state. At fluidization velocity of $0.72 \mathrm{~m} / \mathrm{s}$ particles begins to expand at time $0.25 \mathrm{~s}$ and particle mixes well, it can be seen that further, the bubbles loses its spherical shape and this is due to the strong coalescence and breakage. After reaching the bed surface, the big bubbles collapse and the particles are forces towards the wall. At fluidization velocity of $0.96 \mathrm{~m} / \mathrm{s}$ the bed expands, and more bubbles interacts with the particles which indicates better surface and gas contact, better mixing. At a higher fluidization velocity of 1.2 and $1.44 \mathrm{~m} / \mathrm{s}$ much bigger bubbles are formed, forcing the particles to move close to the wall, resulting in poor mixing and may lead to spout bed. Fig. 9 compares the time-mean voidage distribution vs distance at different bed heights $\mathrm{z}=0.20$, $0.30,0.35$ and $0.40 \mathrm{~m}$ at different fluidization velocity of $0.24,0.48,0.96,1.2$ and $1.44 \mathrm{~m} / \mathrm{s}$. At all the $\mathrm{z}$ heights, start from the velocity of $0.24 \mathrm{~m} / \mathrm{s}$ till velocity of $1.44 \mathrm{~m} / \mathrm{s}$ confirms the same trend of gas volume fraction variation. As can be seen that at $\mathrm{z}=0.20-0.40 \mathrm{~m}$ the time-mean voidage profile becomes flatter at the centre indicating the central region has high gas volume fraction and close to the wall sharp distribution indicates low gas volume fraction. An asymmetry is also observed in all the plots, and this may be due to $25 \mathrm{~s}$ of time-averaging which might be short time-averaging for solid particle distribution in the FBR. The flatter at the centre of the bed at a higher velocity is an indication of the flow being more developed. 

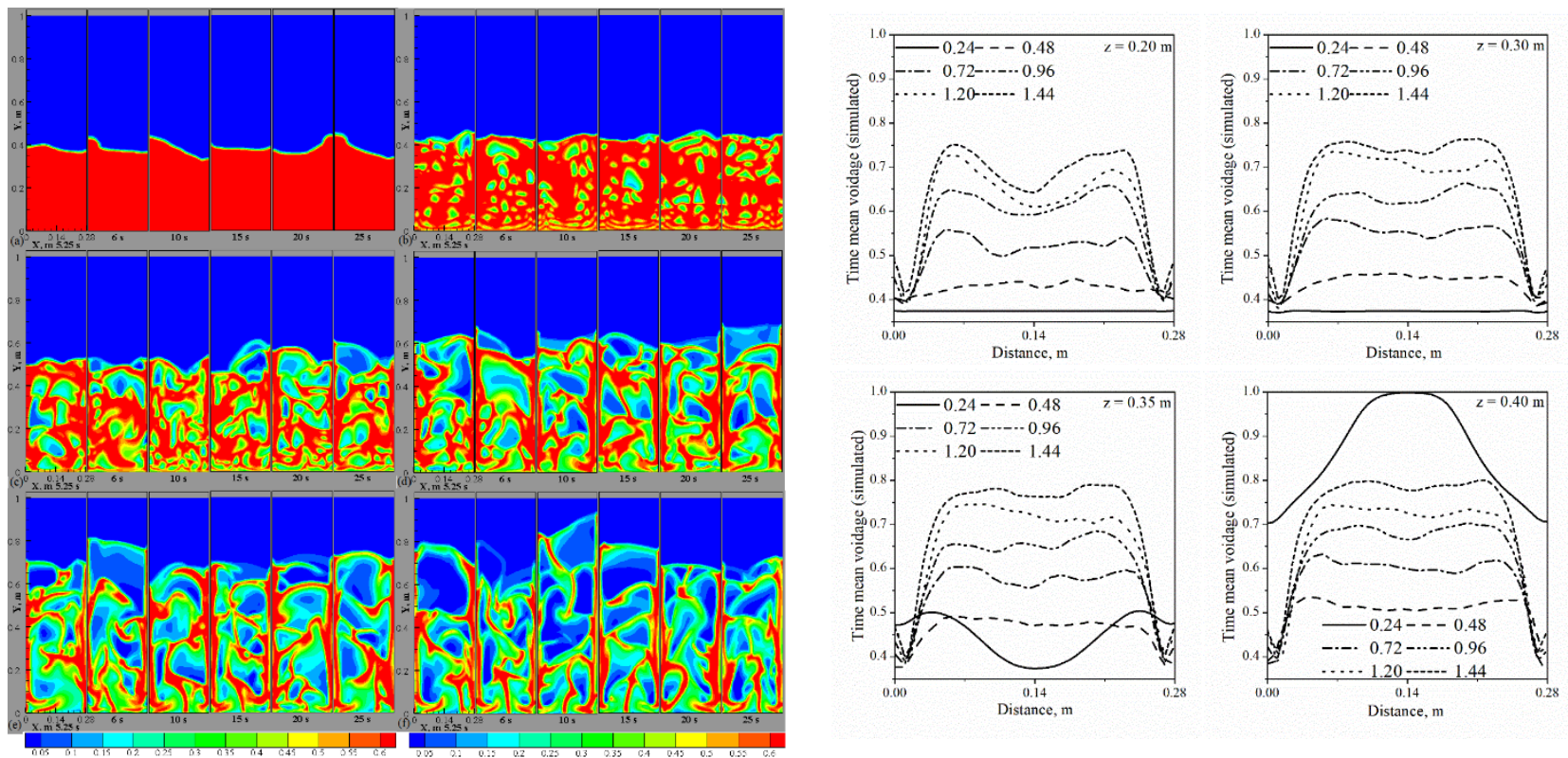

Fig. 6 Simulated instantaneous local solid volume fraction: (a, b \&c) (U = 0.24, 0.48 \& $0.72 \mathrm{~m} / \mathrm{s})$, drag function: Syamlal-O'Brien, $\mathrm{e}_{\mathrm{ss}}$ $=0.905 .25-25 \mathrm{~s}$. Time averaged void fraction profiles at $\mathrm{z}=0.2,0.30,0.35$ and $0.40 \mathrm{~m}$, Simulation parameter: Drag model: SyamlalO'Brien, $\mathrm{U}_{\mathrm{mf}}=0.24,0.48,0.72,0.96,1.2$ and $1.44 \mathrm{~m} / \mathrm{s}$ at $\mathrm{e}_{\mathrm{ss}}=0.90$

\section{Conclusion}

In the present study, 2D CFD simulation of FBR with the particle size of $300 \mu \mathrm{m}$ is performed to understand the solidgas mixing inside FBR. Syamlal-O'Brien model predicts the particle distribution more accurately for the particular fluidization. The fluidization velocity of $0.72-1.2 \mathrm{~m} / \mathrm{s}$ will be the most appropriate operating range, which offers much more solid-gas mixing and more developed flow with reasonable voidage fraction. The present study is based on the range of fluidization velocity with the Syamlal-O'Brien drag model. However, few combinations such as restitution and specularity coefficient, lower time step size and selection of spatial discretization can still be tested to analyze the behaviour of solidgas mixing.

\section{References}

[1] S. Maroufi, B. Khoshandam, R. V Kumar, Ironmak. Steelmak. 2012, 39, 301.

[2] K. Daizo, O. Levenspiel, Fluidization Engineering, 2nd Edition, Stoneham, MA (United States); Butterworth Publishers, United States, 1991.

[3] M. Ishii, NASA Sti/recon Tech. Rep. A 1975, 75, 29657.

[4] M. A. Gilbertson, J. G. Yates, J. Fluid Mech. 1996, 323, 377.

[5] X. Chen, J. Wang, Powder Technol. 2014, 254, 94.

[6] D. Gera, M. Gautam, Y. Tsuji, T. Kawaguchi, T. Tanaka, Powder Technol. 1998, 98, 38.

[7] N. Kobayashi, R. Yamazaki, S. Mori, Powder Technol. 2000, 113, 327.

[8] Y. Kaneko, T. Shiojima, M. Horio, Chem. Eng. Sci. 1999, 54, 5809.

[9] C. C. Pain, S. Mansoorzadeh, C. R. E. De Oliveira, Int. J. Multiph. Flow 2001, 27, 527.

[10] R. B. Bird, Appl. Mech. Rev. 2002, 55, R1.

[11] R. Clift, J. R. Grace, M. E. Weber, 2005.

[12] C. Y. Wen, in Chem. Eng. Prog. Symp. Ser., 1966, pp. 100-111.

[13] M. Syamlal, T. J. O’Brien, in AIChE Symp. Ser, Publ By AIChE, 1989, pp. 22-31.

[14] D. Gidaspow, Multiphase Flow and Fluidization: Continuum and Kinetic Theory Descriptions, Academic Press, 1994.

[15] J. L. Sinclair, R. Jackson, AIChE J. 1989, 35, 1473.

[16] C. M. Hrenya, J. L. Sinclair, AIChE J. 1997, 43, 853.

[17] M. J. V Goldschmidt, J. A. M. Kuipers, W. P. M. van Swaaij, Chem. Eng. Sci. 2001, 56, 571. 
[18] G. A. Bokkers, M. van Sint Annaland, J. A. M. Kuipers, Powder Technol. 2004, 140, 176.

[19] F. Vejahati, N. Mahinpey, N. Ellis, M. B. Nikoo, Can. J. Chem. Eng. 2009, 87, 19.

[20] F. Taghipour, N. Ellis, C. Wong, Chem. Eng. Sci. 2005, 60, 6857.

[21] C. K. K. Lun, S. B. Savage, D. J. Jeffrey, N. Chepurniy, J. Fluid Mech. 1984, 140, 223.

[22] J. Ding, D. Gidaspow, AIChE J. 1990, 36, 523.

[23] S. Vasquez, in ASME 200 Fluids Eng. Div. Summer Meet., 2000.

[24] I. ANSYS, ANSYS FLUENT Release 2009. 